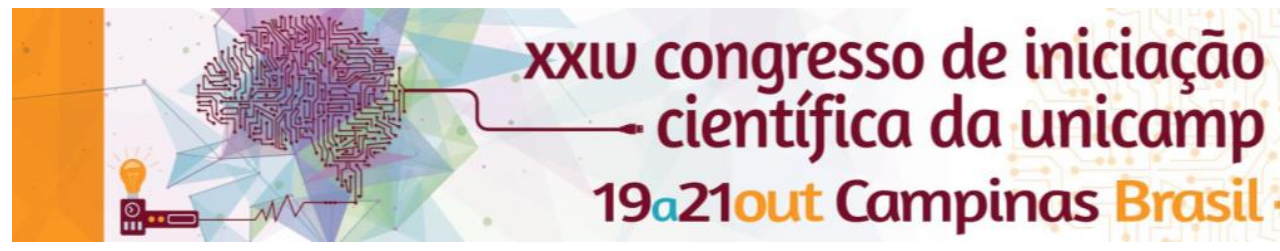

\title{
Sugarcane bagasse hydrolysis at high solids concentration
}

\author{
Nicolas R. Pedrosa*, Daniele L. Machado, Aline C. da Costa
}

\begin{abstract}
High consistency enzymatic hydrolysis of pretreated sugarcane bagasse was studied under some modifications of the usual procedures. At the end of the project, a five-step method was proposed: an enzymatic adsorption followed by a separation of solids; a first hydrolysis of the separated bagasse, another solid/liquid separation and new hydrolysis on the solid. This modified process resulted in hydrolysate with glucose concentration as high as $144 \mathrm{~g} / \mathrm{L}$.
\end{abstract}

\section{Key words:}

Enzymatic hydrolysis, sugarcane bagasse, ethanol.

\section{Introduction}

It is well known that the enzymatic hydrolysis of lignocellulosic materials should yield high glucose concentrations in order to be an economically successful process of bioethanol production. XUE et al. (2012) ${ }^{1}$ and YANG et al., $(2011)^{2}$ proposed alterations of the conventional hydrolysis method, but further evaluations showed that both studies could be improved and combined to achieve a far more interesting result. New procedures involving pretreated sugarcane bagasse were tested to enhance the conversion of cellulose into glucose under a very adverse condition: the high solids concentration. After several modifications of the process, it was possible to overcome this problematic condition and yield very high concentrations of glucose in the end.

\section{Results and Discussion}

Conventional hydrolysis at $5 \%$ and $24,95 \%$ of total solids $(\mathrm{m} / \mathrm{v})$ were compared with the two hydrolysates obtained from the five-step modified procedure, described in the schematic diagram below:

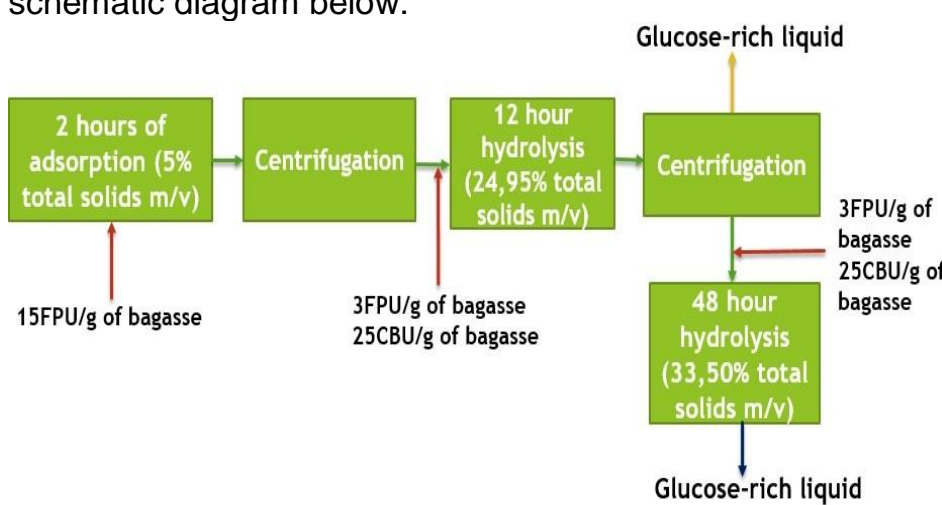

Image 1. Diagram of the modified hydrolysis.

$5 \%$ of total solids $(\mathrm{m} / \mathrm{v})$ was the concentration at the adsorptive-step and $24,95 \%(\mathrm{~m} / \mathrm{v})$ was the concentration observed after the first centrifugation.

The results obtained showed that the procedure described in the image above had more advantages compared with conventional hydrolysis at a concentration of cellulase of 15 $\mathrm{FPU} / \mathrm{g}$ of bagasse and $25 \mathrm{CBU} / \mathrm{g}$ of bagasse.
Chart 1. Glucose concentration obtained (g/L)

\begin{tabular}{|c|c|c|c|c|}
\hline $\begin{array}{c}\text { Time } \\
(\mathrm{h})\end{array}$ & $5 \%(\mathrm{~m} / \mathrm{v})$ & $\begin{array}{c}24,95 \% \\
(\mathrm{~m} / \mathrm{v})\end{array}$ & $\begin{array}{c}5 \text {-step } \\
\text { hydrolysis } \\
\left(1^{\text {st }} \text { stage }\right)\end{array}$ & $\begin{array}{c}5 \text {-step } \\
\text { hydrolysis } \\
\left(2^{\text {nd }} \text { stage }\right)\end{array}$ \\
\hline 12 & $17,97 \pm 0,43$ & $40,59 \pm$ & $54,26 \pm$ & $95,59 \pm 3,16$ \\
& & 2,50 & 2,74 & \\
\hline 24 & $21,82 \pm 0,86$ & $59,33 \pm$ & $71,37 \pm$ & $115,22 \pm 4,36$ \\
& & 1,67 & 3,30 & \\
\hline 48 & $25,59 \pm 0,15$ & $77,63 \pm$ & $83,98 \pm$ & $144,31 \pm 4,31$ \\
& & 2,47 & 4,63 & \\
\hline
\end{tabular}

It is important to mention that, up to 24 hours of hydrolysis, the new procedure ( $1^{\text {st }}$ stage) had clearly better results in comparison with its conventional procedure (at $24,95 \%$ of total solids $(\mathrm{m} / \mathrm{v}))$. Also, the liquid obtained after the new method's fifth-step (i.e. the $2^{\text {nd }}$ stage of hydrolysis) showed a surprisingly high glucose concentration. These facts could be explained by two main reasons: the adsorptionstep is important to ensure the catalytic effect of cellulases and the separation of liquids containing high concentrations of glucose may prevent the inhibition effect from glucose.

\section{Conclusions}

It was possible to develop a process capable of obtaining high concentration of glucose at a high consistency enzymatic hydrolysis of biomass.

This procedure should now be tested in higher scale experiments and also with other types of lignocellulosic materials.

\section{Acknowledgement}

We would like to thank CNPQ for the financial support, Novozymes North America Inc. for providing enzymes and the Bioethanol Science and Technology Laboratory (CTBE) for providing the pretreated sugarcane bagasse and its characterization.

${ }^{1}$ XUE, Ying et al. Split addition of enzymes in enzymatic hydrolysis at high solids concentration to increase sugar concentration for bioethanol production. Journal Of Industrial And Engineering Chemistry, v. 18, n. 2, p.707-714, mar. 2012.

${ }^{2}$ YANG, Jing et al. Three-stage enzymatic hydrolysis of steam-exploded corn stover at high substrate concentration. Bioresource Technology, v. 102, n. 7 p.4905-4908, abr. 2011. 